\title{
TAXA DE GESTAÇÃO EM NOVILHAS NELORE SINCRONIZADAS PARA IATF E INSEMINADAS COM SÊMEN RESFRIADO E CONGELADO
}

\author{
Aline Silva Fujita1, Romildo Romualdo Weiss ${ }^{1}$, Paulo Rossi Junior ${ }^{1}$, Luiz Ernandes \\ Kozicki $^{2}$, Felix Vilas Novas Greselle ${ }^{1}$, Melina Andrea Formighieri Bertol ${ }^{1}$
}

\author{
1 UFPR \\ 2 PUC-PR \\ Correspondência: Romildo Romualdo Weiss: rrweiss@bol.com.br
}

RESUMO: O presente estudo teve como objetivos: comparar as taxas de gestação de novilhas Nelore após a inseminação artificial em tempo fixo com sêmen resfriado a $5^{\circ} \mathrm{C}$ ou congelado a 196드, avaliar o diâmetro do folículo pré-ovulatório entre os grupos, verificar a influência das concentrações séricas de cortisol na taxa de gestação e a taxa de ovulação gerada na utilização de acetato de deslorelina. Para isso, 96 novilhas foram divididas em dois grupos, GR $(n=47)$ e GC $(n=49)$ e inseminadas com sêmen resfriado e congelado, respectivamente. O protocolo utilizado foi: Dia $0(\mathrm{D} 0)=\mathrm{BE}+$ implante auricular de norgestomet; $\mathrm{D} 8$ = retirada do implante + PGF2 $\alpha+$ eCG; $\mathrm{D} 10$ = acetato de deslorelina; D11 = IATF. Para avaliar a correlação das concentrações séricas de cortisol e a taxa de gestação foram efetuadas análises por meio do Teste de ELISA por competição. O sêmen foi coletado de um único touro da raça Nelore, por meio de eletroejaculação, e dividido em duas frações, acrescentando diluente à base de gema de ovo, sem crioprotetor (GR), e com crioprotetor (glicerol) (GC) e em seguida foi realizado o envase em palhetas de $0,5 \mathrm{~mL}$, com 30 milhões de espermatozoides viáveis por palheta. Não houve diferença $(P \geq 0,05)$ entre a taxa de gestação do grupo GR $(48,94 \%)$ e GC $(46,94 \%)$. Houve diferença $(P<0,05)$ entre os diâmetros de folículos pré-ovulatórios de GR e GC. Altas concentrações de cortisol foram detectadas. Concluiu-se que não houve diferença na taxa de gestação entre novilhas inseminadas com sêmen resfriado e com sêmen congelado, que não há relação entre as concentrações séricas de cortisol com as taxas de gestação, que há diferença entre o diâmetro dos folículos pré-ovulatórios entre GC e GR, e que o acetato de deslorelina promoveu uma taxa de ovulação de 40,6\% em novilhas Nelore.

Palavras-chave: acetato de deslorelina; bovino; eletroejaculação; folículo

\section{PREGNANCY RATES IN NELORE HEIFERS SYNCHRONIZED FOR TAI AND INSEMINATED WITH CHILLED AND DEEP-FROZEN SEMEN}

\begin{abstract}
The present study aimed to compare the pregnancy rate after timed artificial insemination (TAI) using chilled semen $\left(5^{\circ} \mathrm{C}\right)$ and deep-frozen semen $\left(-196^{\circ} \mathrm{C}\right)$, evaluate the correlation between the pregnancy rates and the diameters of pre-ovulatory follicles in Nelore heifers, verify the influence of cortisol levels in pregnancy rate and the efficiency of the deslorelin acetate as an ovulation inductor. Two groups of heifers were made, GR $(n=47)$ and $G C(n=49)$, to be inseminated with chilled semen and deep-frozen semen, respectively. The hormonal protocol consisted on: Day $0(D 0)=E B+$ ear norgestomet implant; D8 = withdraw of implant + PGF2 $\alpha+$ eCG; D10 = deslorelin acetate; D11 = TAl. To evaluate levels of serum cortisol, the competitive ELISA test was used. The semen was collected from a single Nelore bull, through eletroejaculation process, divided in two parts and diluted with egg yolk based diluents without crioprotectant (GR), and with crioprotectant (GC) stored in straws of $0.5 \mathrm{~mL}$ and 30 million viable spermatozoa each. There was no statistical significance difference $(P \geq 0.05)$ between the pregnancies of $G R(48.94 \%)$ and GC $(46.94 \%)$. There was statistical significance $(P<0.05)$ between the diameters of pre-ovulatory follicles of GR and GC, but there was no statistical significance for the relation with pregnancy percentages. High levels of serum cortisol were found. In conclusion there was no difference in the pregnancy rate between the groups inseminated with chilled or deep-frozen semen, there was no relation between the levels of serum cortisol with the number of pregnant heifers, there was difference between the diameter of the pre-ovulatory follicles for GR and GC, and the use of deslorelin acetate was effective to promote a ovulation rate of $40.6 \%$ for Nelore heifers.
\end{abstract}

Key Words: deslorelin acetate; bovine; eletroejaculation; follicle 

resfriado e congelado

\section{INTRODUÇÃO}

\section{A inseminação artificial (IA)} apresenta vantagens em relação à monta natural no que diz respeito à sanidade dos animais, custo diminuído em relação ao transporte genético, e a organização de trabalho, além do potencial de melhora na produção (Baruselli et al., 2008).

Ainda que a IA seja amplamente difundida, no Brasil apenas 9\% das fêmeas bovinas em idade reprodutiva são inseminadas (ASBIA, 2010). A inseminação artificial em tempo fixo (IATF) induz a regulagens hormonais e permite maior controle sobre as datas de fertilização e nascimento, com maior acurácia do momento da ovulação, otimizando o trabalho a campo, sem que haja comprometimento na fertilidade (Sá Filho et al., 2010). No Brasil, a maioria das inseminações artificiais em bovinos é feita com sêmen congelado, técnica disseminada mundialmente, implicando, porém em taxas de fecundidade consideradas medianas.

$\mathrm{Na}$ maioria dos países em desenvolvimento, a IA foi introduzida em pequena escala nas décadas de 1950 e 1960, utilizando-se sêmen fresco ou conservado à temperatura ambiente, e que no final da década de 1970 houve colaboração de investimento internacional para o processamento de sêmen congelado. Assim, sem avaliar a viabilidade de manutenção, tornou-se necessária a utilização de empresas para a capacidade operacional de preservação do material genético, e a vantagem do estoque de sêmen por tempo prolongado convenceu os produtores a praticar a IA com sêmen congelado em vez de sêmen líquido (resfriado ou a fresco) (Schuh, 1992).

Após a diluição e a criopreservação das células espermáticas há queda na viabilidade, pois ocorrem danos na integridade das membranas que reduzem a motilidade interferindo na sobrevivência e na capacidade fecundante dos espermatozoides (Foote e Bratton, 1960). Assim sendo, a utilização de sêmen resfriado seria uma alternativa com possibilidade de alcance de maior porcentagem de prenhez entre as fêmeas, contanto que haja proximidade suficiente entre o doador de sêmen e fêmeas a serem inseminadas.

Watson (2000) afirmou que cerca de 40 a $50 \%$ da população de espermatozoides não sobrevivem à criopreservação mesmo utilizando-se protocolos de otimização. Quando comparamos o número de espermatozoides móveis e viáveis após o processo de congelamento, os resultados são mais pobres que no sêmen fresco. Choque térmico pelo frio é um estado extremo de estresse, esse estresse nas membranas é continuado abaixo de $8^{\circ} \mathrm{C}$, pois é sabido que a maior parte das mudanças de fase das partículas celulares ocorre entre 5 e $158^{\circ} \mathrm{C}$ (Drobnis et al., 1993), e esta é uma variação de temperatura importante para os danos dependentes de temperatura.

Considerados estes danos às membranas, Crespilho (2010) afirmou que o sêmen bovino refrigerado pode permitir maior número de espermatozóides íntegros, e assim se justificaria a superioridade em relação ao sêmen congelado, devido à maior capacidade de fertilização. Além disso, Crespilho et al. (2006) relataram maior viabilidade espermática pósdescongelamento na utilização de um meio diluente à base de gema de ovo em relação ao diluidor com tris-gema de ovo-frutose, quando consideradas análises de movimento linear espermático, que refletem 0 ambiente bioquímico e as condições físicas a que são submetidos os espermatozóides. Papa et al. (2008) analisaram dados de experimentos realizados comparando diferentes diluentes e suas capacidades 
de preservação celular dos espermatozóides após congelamento, e afirmaram que o diluente à base de gema de ovo tem melhor efetividade sobre a preservação do que outros diluidores como os à base de lecitina de soja e o Tris-gema de ovo-frutose, que é atualmente o mais usado no mundo.

Em relação à utilização de novilhas em protocolos de IATF, é de grande importância à manutenção e o desenvolvimento de sua eficiência reprodutiva, dada a necessidade contínua de reposição de matrizes quando é sabido que a viabilidade financeira da pecuária de corte está vinculada à produção de bezerros (Sá Filho et al., 2010), e em seguida essa categoria animal tende a ser mais agitada quando criada em sistema extensivo. Cooke et al. (2011) reportaram que 0 temperamento agitado, associado com respostas fisiológicas e comportamentais tem influência negativa na eficiência reprodutiva de vacas de corte. A agitação pode atrapalhar desde a ingestão alimentar e o estado nutricional, e pode também desencadear respostas neuroendócrinas de estresse, como a liberação elevada de cortisol, que podem atrapalhar os processos fisiológicos relacionados à fertilidade (Cooke et al., 2009; Dobson et al., 2001).

O acetato de deslorelina (análogo do $\mathrm{GnRH}$ ) apresenta multiplicidade de efeitos, e quando especificamente se trata de ovários, apresenta a indução de ovulação. Ambrose et al. (1998) sugeriram que, quando utilizado como última administração no protocolo hormonal em vacas de leite, o acetato de deslorelina melhorou a diferenciação do corpo lúteo, resultando em maior fase lútea e maior produção de progesterona.

Neste contexto, o presente trabalho teve como objetivos: avaliar a diferença entre a taxa de gestação de novilhas inseminadas com sêmen resfriado e com sêmen congelado; verificar a influência das concentrações séricas de cortisol e os diferentes diâmetros dos folículos dominantes préovulatórios na taxa de gestação; e a efetividade do acetato de deslorelina como indutor de ovulação em novilhas de corte.

\section{MATERIAL E MÉTODOS}

O experimento foi realizado na Fazenda Primavera, no município de Lambari D'Oeste - MS, Brasil (latitude 1514'1" S, longitude 57³1'21" O). Esta é uma região de clima tropical cujas médias de temperatura variam anualmente entre 32,4 e $20^{\circ} \mathrm{C}$, podendo apresentar extremos entre 42 e $10^{\circ} \mathrm{C}$ (Santos et al., 2010). A umidade relativa do ar normalmente se encontra em torno dos $77 \%$ (entre os meses de agosto e dezembro), porém a precipitação pluvial pode ser próxima à zero entre os meses de junho e julho (INMET, 2012).

Foram utilizadas 96 novilhas e um touro da raça Nelore (Bos taurus indicus), os animais eram mantidos em sistema de pastejo em Brachiaria sp. e suplementação com sal mineral e água ad libitum.

As fêmeas pesavam em média $325 \mathrm{~kg}$ e foram avaliadas por palpação retal e ultrassonografia trans-retal (aparelho ALOKA SSD-500, transdutor linear de $5 \mathrm{MHz}$ ), para verificação de função ovariana e normalidade do trato reprodutivo.

Após a avaliação, as novilhas foram divididas ao acaso em dois grupos: grupo GR $(n=47)$, para IA com sêmen resfriado $\left(5^{\circ} \mathrm{C}\right)$; e grupo $\mathrm{GC}$ $(n=49)$, para IA com sêmen congelado ($\left.196^{\circ} \mathrm{C}\right)$.

O touro doador do sêmen foi avaliado previamente sob os aspectos de estado de condição corporal, trato 

resfriado e congelado

reprodutivo e viabilidade espermática. Para a coleta da amostra de sêmen por eletroejaculação o touro foi submetido à lavagem prepucial com soro fisiológico aquecido a $35^{\circ} \mathrm{C}$. Imediatamente após a coleta o sêmen foi avaliado sob os aspectos de volume (em tubo graduado de $15 \mathrm{~mL}$ ), motilidade de massa, vigor, motilidade progressiva (em microscópio óptico sobre lâmina e lamínula aquecida a $\left.36^{\circ} \mathrm{C}\right)$ e concentração espermática (Câmara de Neubauer).

A amostra foi então separada em duas frações; a primeira, a ser utilizada para GR, foi diluída com diluente à base de gema de ovo, em fração sem crioprotetor. A fração utilizada para o grupo GC empregou a mesma base de diluente, porém contendo crioprotetor (glicerol). Após a diluição foi realizado o envase em palheta média inseminante de $0,5 \mathrm{~mL}$ contendo 30 milhões de espermatozoides viáveis cada. Todas as palhetas de sêmen foram resfriadas em recipiente próprio para a redução de temperatura de $35^{\circ} \mathrm{C}$ para $5^{\circ} \mathrm{C}$ e manutenção da temperatura a $5^{\circ} \mathrm{C}$ por quatro horas para estabilização metabólica dos espermatozóides.

O sêmen resfriado foi mantido durante 24 horas à temperatura de $5^{\circ} \mathrm{C}$, até que fosse utilizado para a inseminação. $O$ sêmen congelado foi submetido a quatro horas de estabilização a $5^{\circ} \mathrm{C}$, sendo então primeiramente realizada a queda de temperatura de $5^{\circ} \mathrm{C}$ para $-20^{\circ} \mathrm{C}$, e, em seguida, procedeu-se a manutenção das palhetas a $5 \mathrm{~cm}$ do vapor de nitrogênio durante 20 minutos, em recipiente fechado de boa manutenção térmica. Após este período, as palhetas foram imersas diretamente no $\mathrm{N} 2$, e inseridas no botijão de conservação para a utilização posterior.

O reaquecimento do sêmen antes da inseminação foi feito mediante imersão das palhetas em água a $36^{\circ} \mathrm{C}$ por 30 segundos.
As novilhas foram submetidas ao protocolo de quatro manejos e 11 dias de duração para a sincronização da ovulação e inseminação artificial (Figura 1).

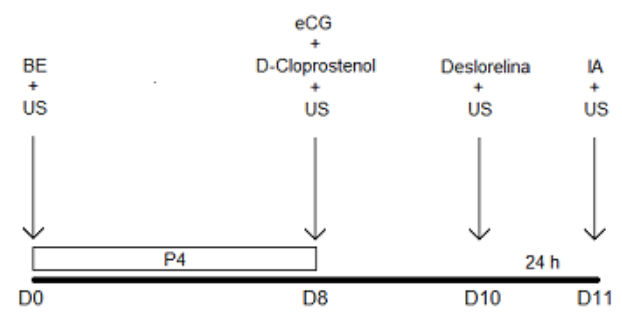

Figura 1- Protocolo hormonal para inseminação artificial em tempo fixo: sendo, BE=benzoato de estradiol; US=ultrassonografia sendo, $\quad B E=$ benzoato de estradiol;
P4=implante auricular de norgestomet; eCG=gonadotrofina coriônica equina; IA=inseminação artificial.

No dia da inseminação (D11), o GR foi inseminado com sêmen resfriado, e o GC com sêmen congelado.

Foram realizadas análises ultrassonográficas durante o protocolo (em D0, D8, D10 e D11), visando acompanhar a atividade ovariana e a dinâmica do crescimento folicular. O diagnóstico de gestação foi realizado ao 28ํ dia após IA, via ultrassonografia trans-retal.

Paralelamente ao protocolo foram coletadas amostras de sangue de um grupo aleatório de 13 novilhas visando à determinação hormonal de cortisol sérico, nos dias D0, D8 e D11. Os soros foram obtidos por meio da centrifugação do sangue recém-colhido por venopunção, em rotação de 5000 rpm, durante 10 minutos, e conservados a $-20^{\circ} \mathrm{C}$ até as análises laboratoriais, determinadas pelo método do Teste de ELISA por competição. As análises foram realizadas no Laboratório de Microbiologia e Ornitopatologia da Universidade Federal do Paraná.

As análises estatísticas para avaliar diferenças entre a taxa de gestação entre os grupos foram realizadas pelo teste do Qui-quadrado com nível de significância de 5\%. A avaliação das dimensões dos folículos pré-ovulatórios e as diferenças entre as 
concentrações séricas de cortisol foram submetidas à ANOVA e as médias comparadas pelo teste de Tukey a $5 \%$ de significância. O programa utilizado foi o Statistix 9.

\section{RESULTADOS E DISCUSSÃO}

O sêmen colhido do touro encontrou-se em conformidade com os parâmetros mínimos descritos para animais de raças zebuínas (Fonseca, 1997; CBRA, 1998; Lopes et al., 2009; Tabela 1).

À microscopia óptica, os espermatozóides das palhetas de sêmen resfriado e reaquecido a $36^{\circ} \mathrm{C}$ apresentaram valores de motilidade progressiva de $85 \%$ e vigor 4 ; as de sêmen congelado apresentaram motilidade progressiva de $50 \%$ e vigor 3 (Tabela 2). Nota-se que o processo de criopreservação afetou de maneira mais severa a motilidade dos espermatozóides que o processo de refrigeração.

Tabela 1 - Parâmetros reprodutivos do touro Nelore doador de sêmen.

\begin{tabular}{lc}
\hline Parâmetros avaliados & Valores \\
\hline Circunferência escrotal & $37 \mathrm{~cm}$ \\
Volume de ejaculado & $9,5 \mathrm{~mL}$ \\
Motilidade inicial & $95 \%$ \\
Vigor inicial & 4 \\
Defeitos menores & $2 \%$ \\
Def eitos maiores & $9,5 \%$ \\
\hline
\end{tabular}

Tabela 2 - Valores de motilidade progressiva e vigor após reaquecimento do sêmen.

\begin{tabular}{ccc}
\hline Amostra & Motilidade progressiva & Vigor \\
\hline Sếmen Resfriado & $85 \%$ & 4 \\
Sêmen Congelado & $50 \%$ & 3 \\
\hline
\end{tabular}

Maziero et al. (2009), afirmam a existência de uma clara associação entre o potencial de fertilização e o movimento espermático de amostras seminais, na qual se observa relação entre ausência de movimento e quadros de infertilidade.

Boland e Gordon relataram que a taxa de fertilidade foi maior e a taxa de mortalidade de embriões, menor, ao se usar sêmen fresco ou resfriado, quando comparado ao sêmen congelado. Em experimento com 48 novilhas, divididas em dois grupos, foram verificadas porcentagens de embriões viáveis de 75,0 e $62,5 \%$, em fêmeas abatidas um mês após a inseminação com sêmen fresco e congelado.

O total de novilhas prenhes considerando-se os dois grupos foi de 46 animais, ou $47,92 \%$, percentual similar ao observado em novilhas por Sá Filho et al. (2010), Sá Filho et al. (2008b) e Torres-Júnior et al. (2005).

Sá Filho et al. (2008b), observaram que no início do tratamento visando à IATF a condição corporal dos animais tem efeito significativo sobre 0 diâmetro folicular no momento da IATF, e as novilhas com escore de condição corporal igual ou superior a 3,25 apresentaram maior diâmetro folicular e taxas de prenhez mais elevadas.

No período experimental as novilhas estavam em fase de recuperação orgânica proveniente de uma estiagem forte ocorrida nos meses anteriores (junho a novembro), nos quais a chuva foi escassa e a umidade relativa do ar encontrava-se em torno dos 50\%. Restle et al. (1999) constataram que a reprodução de novilhas, atrelada à sua puberdade, se dá por consequência da velocidade de ganho de peso, que por sua vez está condicionada ao meio ambiente. Costa e Silva et al. (2010) relatam que o comportamento sexual das fêmeas pode ser diminuído por exposição a temperaturas altas, inclusive com redução da manifestação do tempo de cio.

O grupo GR e o grupo GC apresentaram 23 gestações cada um, ou seja, $48,94 \%$ e $46,94 \%$ respectivamente. Não houve diferença entre os grupos $(P>0,05)$, conforme observado na Tabela 3. Apesar da motilidade espermática e vigor do sêmen após reaquecimento ter sido maior no sêmen resfriado que no 

resfriado e congelado

congelado, não houve diferença refletida na taxa de gestação, como sugerido por Boland e Gordon (1979) e Maziero (2009). Crespilho (2010) obteve resultados significativamente maiores em gestações quando utilizou sêmen resfriado por até 24 horas em relação ao sêmen congelado, e considerou o sêmen resfriado como alternativa viável econômica e biologicamente. Garcia et al. (1999) obtiveram resultados favoráveis com a utilização de sêmen resfriado por 8 horas, porém quando utilizaram sêmen resfriado por 32 horas não encontraram diferenças com 0 sêmen congelado.

Nas Tabelas 3 e 4 podemos observar os resultados da mensuração do diâmetro dos folículos dominantes (FD) pré-ovulatórios no dia D10 (dia anterior ao da inseminação) e também o diâmetro dos folículos ovulatórios (FO) no dia D11.

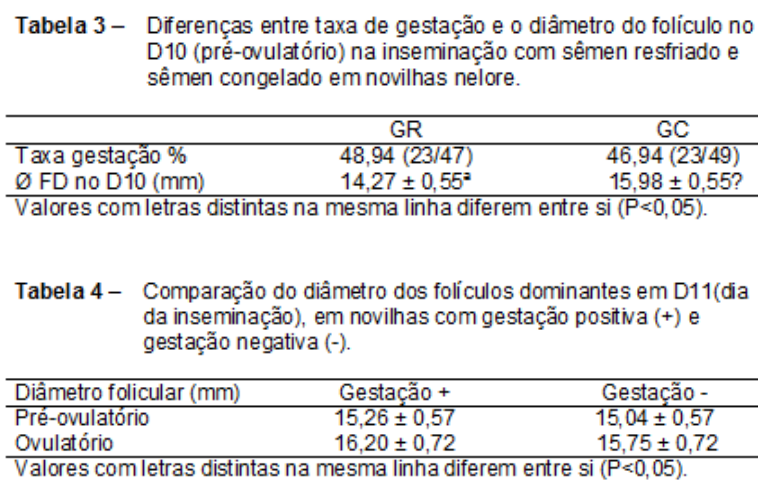

Houve diferença $(P<0,05)$ entre os diâmetros de folículos de GR e GC, sendo que o GC apresentou maior média de diâmetros foliculares.

Em relação à ovulação, o acetato de deslorelina mostrou-se eficaz no D10 do protocolo para induzir a ovulação no D11 quando $40,6 \%$ das novilhas já haviam ovulado. Estas observações estão de acordo com estudos prévios sobre a utilização do acetato de deslorelina como indutor de ovulação. Bartolome et al. (2004) relataram que implantes de deslorelina estimularam desenvolvimento de corpos lúteos normais e induziram ovulação em vacas leiteiras não lactantes. Melo et al. (2005) compararam o uso de deslorelina ao extrato de pituitária equina e constataram que ambos foram eficientes à ovulação em éguas.

No caso das novilhas que apresentaram ovulação antes da inseminação (FD ovulatórios em D11), também não houve diferenças quando relacionadas com a taxa de gestação. Roelofs et al. (2006) e Dalton e Saacke (2007) sugeriram que, para melhorar os índices de prenhezes, a IA deve ser realizada próximo ao momento da ovulação (aproximadamente 30 horas após 0 início do cio), mas preferencialmente anterior a ela, para impedir que o oócito envelheça e permitir a melhoria da disponibilidade espermática para fecundação.

Em relação às concentrações séricas de cortisol os valores médios encontrados para todos os animais avaliados foram: $\mathrm{D0}=199,24 \pm 29,83$, D8 $=87,20 \pm 24,11$, e D11 = 177,68 \pm 36,35 , os valores individuais podem ser observados na Tabela 5 . Neste experimento encontramos concentrações elevadas de cortisol. Isso pode ser proveniente do uso de novilhas, assim como observado por Tenessen et al. (1984), que afirmaram que novilhas e vacas tem concentrações séricas de cortisol mais elevadas que touros, bois e bezerros. Além disso, verificaram que o manejo do animal no início de sua vida tem efeito mais tarde sobre a sua resposta fisiológica a situações estressoras. As novilhas utilizadas em nosso experimento foram criadas em manejo extensivo, e se deslocavam correndo por aproximadamente 1,5 a $2 \mathrm{~km}$ até a chegada ao curral de manejo. Grandin (1997) afirmou que animais criados em manejo constante tinham menores concentrações de cortisol após a contenção, quando comparados a animais que eram criados soltos. 


\begin{tabular}{cccccc} 
Tabela 5 - Niveis séricos de cortisol em D0, D8 e D11, média das \\
avaliações (D0; D8; D11) e resultado de gestação individual. \\
\hline Novilha & D0 & D8 & D11 & Média & Gestaç̃o \\
\hline 1 & 197,59 & 46,05 & 173,42 & 197,59 & + \\
2 & 142,51 & 84,16 & 96,03 & 107,57 & + \\
3 & 70,52 & 42,45 & 166,65 & 93,21 & - \\
4 & 224,94 & 91,77 & 303,24 & 206,65 & + \\
5 & 182,97 & 53,40 & 168,87 & 135,08 & - \\
6 & 226,00 & 35,00 & 176,53 & 145,85 & + \\
7 & 259,72 & 106,96 & 286,78 & 217,82 & - \\
8 & 307,95 & 130,29 & 100,09 & 179,45 & + \\
9 & 251,02 & 32,86 & 286,89 & 190,26 & - \\
10 & 167,52 & 207,04 & 94,85 & 156,47 & - \\
11 & 230,96 & 112,84 & 212,67 & 185,49 & + \\
12 & 197,59 & 129,19 & 91,02 & 139,27 & - \\
13 & 130,85 & 61,57 & 152,70 & 115,04 & + \\
\hline
\end{tabular}

Os valores de cortisol plasmático variaram muito entre os autores pesquisados; Dunn (1990) encontrou valores acima de $93 \mathrm{ng} / \mathrm{mL}$ ao manter bovinos em decúbito dorsal durante apenas 103 segundos, Grandin (1997) revisando autores encontrou valores diferentes em diversos experimentos, variando de $0,5 \mathrm{ng} / \mathrm{mL}$ a $100 \mathrm{ng} / \mathrm{mL}$.

Segundo Grandin (1997), as concentrações de cortisol são altamente variáveis e comparações de valores absolutos não deveriam ser feitas entre estudos diferentes, já que o estresse e as condições ambientais e de manejo variam a cada experimento. Esses autores ressaltaram que o cortisol é uma medida dependente do tempo, e que seus valores levam de 10 a 20 minutos para atingir valores de pico. Assim, procedimentos rápidos seriam terminados antes mesmo dos valores de cortisol subirem.

Apesar do número reduzido de animais avaliados, as concentrações séricas de cortisol apresentadas pelas novilhas durante todo o manejo para a IATF não demostraram tendência a diferir entre as novilhas que apresentaram gestação positiva $(162,52$ $\pm 18,46)$ ou negativa $(155,35 \pm 20,05)$.

No presente estudo a taxa de gestação apresentada pelas novilhas da raça Nelore após inseminação com sêmen resfriado ou congelado $e$ processado a campo, foi satisfatória e similar à descrita em outros trabalhos em condições semelhantes a este (Baruselli et al., 2006; Claro Filho et al., 2010; Sá Filho et al., 2010).

\section{CONCLUSÃO}

Quando comparadas as taxas de prenhez relativas à inseminação artificial em tempo fixo utilizando o sêmen resfriado e o sêmen congelado, não foram observadas diferenças estatísticas significativas. Houve diferença significativa $(P<0,05)$ entre os diâmetros dos folículos pré-ovulatórios dos grupos inseminados com sêmen resfriado e congelado. Os níveis elevados de cortisol sérico não tiveram relação com a quantidade de prenhezes apresentadas pelas novilhas. Pôde-se verificar a eficiência do uso do acetato de deslorelina em novilhas Nelore, com uma taxa de ovulação de 40,6\%.

\section{NOTAS INFORMATIVAS}

Protocolo de aprovação da pesquisa pela Comissão de ética no uso animal - SCA número 045/2010.

\section{REFERÊNCIAS}

AMBROSE, J.D.; PIRES, M.F.; MOREIRA, F.et al. Influence of deslorelin ( $\mathrm{GnRH}$-agonist) implant on plasma progesterone, first wave dominant follicle and pregnancy in dairy cattle. Theriogenology, v.50, n.7, p.1157-1170, 1998.

ASBIA - Associação Brasileira de Inseminação Artificial. Relatório estatístico de exportação, importação e comercialização de sêmen.

2010. Disponível em:

<http://www.asbia.org.br/novo/upload/mercado/r elatorio2010.pdf> Acesso em: 09/05/2011.

Associação Brasileira das Indústrias

Exportadoras de Carne. ABIEC. 2009. Pecuária Brasileira. Disponível em:

<http://www.abiec.com.br> Acesso em: 26/09/2010.

BARTOLOME, J.A.; SANTOS, J.E.P.; PANCARCI, S.M. et al. Induction of ovulation in nonlactating dairy cows and heifers using different doses of a deslorelin implant. Theriogenology, v.61, p.407-419, 2004.

BARUSELLI, P.S.; AYRES, H.; SOUZA, A.H. et al. Impacto da IATF na eficiência reprodutiva em bovinos de corte. In: Biotecnologia da reprodução em bovinos ( 2 ㄴ Simpósio 

resfriado e congelado

Internacional de Reprodução Animal Aplicada) Anais... Londrina, 2006, p. 113-132.

BOLAND, M.P.; GORDON, I. Fertilization and embryo survival in the beef heifer. Animal Breeding Research Report, v.1976-77, p.7172, 1979.

BORGES, A.M. Influência de diferentes manejos e tratamentos hormonais na dinâmica ovariana durante o ciclo estral e no anestro pós-parto de vacas Gir e Nelore. 136f. Viçosa, 2001. Tese (doutorado). PósGraduação em Zootecnia, Universidade Federal de Viçosa.

BORGES, M.C.B. Efeito do estradiol associado ao progestágeno sobre a taxa de sincronização do estro, de ovulação e prenhez em vacas zebuínas lactantes no pósparto. 48f. Viçosa, 2006. Dissertação (mestrado). Pós-Graduação em Medicina Veterinária, Universidade Federal de Viçosa.

CBRA - Colégio Brasileiro de Reprodução Animal. Manual para exame andrológico e avaliação do sêmen animal. Belo Horizonte: Colégio Brasileiro de Reprodução Animal. 2. ed. 1998. 49 p.

CLARO JÚNIOR, I.; SÁ FILHO, O.G.; PERES, R.F.G. et al. Reproductive performance of prepubertal Bos indicus Heifers after progesterone-based treatments.

Theriogenology, v.74, n.6, p.903-911, 2010.

COOKE, R.F.; BOHNERT, D.W.; MENEGHETTI, M.et al. Effects of temperament on pregnancy rates to fixed-timed $\mathrm{Al}$ in Bos indicus beef cows. Livestock Science, v.142, n.1-3, p.108-113, 2011.

COSTA E SILVA, E.V.; KATAYAMA, K.A.; MACEDO, G.G. et al. Efeito do manejo e de variáveis bioclimáticas sobre a taxa de gestação em vacas receptoras de embriões. Ciência Animal Brasileira, v.11, n.2, p.280-291, 2010.

CRESPILHO, A.M. Avaliação de diferentes metodologias de preservação do sêmen bovino para a utilização em programas de inseminação artificial em tempo-fixo (IATF). 2010. Botucatu, 97f. Tese (Doutorado) Universidade Estadual Paulista, Faculdade de Medicina Veterinária e Zootecnia.

CRESPILHO, A.M.; PAPA, F.O.; ALBERTI, K. et al. Eficiência comparativa entre dois diluidores para a congelação de sêmen bovino sobre os padrões de motilidade e integridade de membrana plasmática. ARS veterinária, v.22, n.3, p.229-235, 2006.

DALTON, J.C. Semen evaluation and fertility in the field. Biotecnologia da Reprodução em
Bovinos (4ํㅗํ Simpósio Internacional de Reprodução Animal) Anais... Londrina, p.101116, 2010.

DALTON, J.C.; SAAKE, R.G. Parâmetros da qualidade do sêmen para programas de sincronização. In: Curso novos enfoques na produção e reprodução de bovinos. Anais... Uberlândia, p.154-161, 2007.

DOBSON, H.; TEBBLE, J.E.; SMITH, R.F.et al. Is stress really all that important?.

Theriogenology, v.55, n.1, p.65-73, 2001.

DROBNIS, E.Z.; CROWE, L.M.; BERGER, T. et al. Cold shock damage is due to lipid phase transitions in cell membranes - a demonstration using sperm as a model. The Journal of Experimental Zoology, v.265, n.4, p.432-437, 1993.

DUNN, C.S. Stress reactions of cattle undergoing ritual slaughter using two methods of restraint. Veterinary Record, v.126, n.21, p.522, 1990.

FONSECA, V.O.; SANTOS, N.R.; MALINSKI, P.R. Classificação andrológica de touros zebus (Bos taurus indicus) com base no perímetro escrotal e características morfo-físicas do sêmen. Revista Brasileira de Reprodução Animal, v.21, n.2, p.36-39, 1997.

FOOTE, R.H.; BRATTON, R.W. Survival of bovine spermatozoa stored at 5 and $25^{\circ} \mathrm{C}$ in extenders containing varying levels of egg yolk, glucose, glycine, glycerol, citrate and other salts. Journal of Dairy Science, v.43, n.9, p.13221329, 1960.

GARCIA, A.R.; ARRUDA, R.P.; MADUREIRA, E.H.et al. Influência do uso de sêmen resfriado e da aplicação de $\mathrm{GnRH}$ sobre a taxa de prenhez de novilhas Nelore inseminadas em tempo-fixo. Revista Brasileira de Reprodução Animal, v.23, n.3, p.342-344, 1999.

GARCIA, A.R.; ARRUDA, R.P.; MADUREIRA, E.H. et al. Influência do uso de sêmen resfriado e da aplicação de GnRH sobre a taxa de prenhez de novilhas Nelore inseminadas em tempo-fixo. Revista Brasileira de Reprodução Animal, v.23, n.3, p.342-344, 1999.

GRANDIN, T. Assesment of stress during handling and transport. Journal of Animal Science, v.75, n.1, p.249-257, 1997.

INSTITUTO NACIONAL DE METEOROLOGIA INMET. Ministério da agricultura, pecuária e abastecimento. 2012. Disponível em: <www.inmet.gov.br>.

LOPES, F.G.; GUIMARÃES, J.D.; COSTA, E.P. et al. Avaliação andrológica por pontos e 
comportamento sexual em touros da raça Nelore. Revista Brasileira de Zootecnia, v.38, n.6, p.1018-1025, 2009.

MAZIERO, R.R.D.; CRESPILHO, A.M.; FREITAS DELL'AQUA, C. P. et al. Análise de sêmen bovino e sua relação com a fertilidade. Revista Brasileira de Reprodução Animal, n.5, p.5-10, 2010.

MELO, C.M.; PAPA, F.O.; MEDEIROS, A.S.L. et al. Efeito da deslorelina e do extrato de pituitária equina na indução da ovulação em éguas. In: Reunião Anual do SBTE, 2005, Acta Scientiae Veterinariae, v.33, n.2, p.193, 2005.

PAPA, F.O.; CRESPILHO, A. M.; FREITAS DELL'AQUA, C. P. et al. Impacto do sêmen no sucesso dos programas de IATF: métodos básicos e avançados de avaliação.

Biotecnologia da Reprodução em Bovinos (3ำ Simpósio Internacional de Reprodução Animal Aplicada) Anais...Londrina, p.78-94, 2008.

RESTLE, J.; POLLI, V.A.; SENNA, D.B. Efeito de grupo genético e heterose sobre a idade $\mathrm{e}$ peso à puberdade e sobre o desempenho reprodutivo de novilhas de corte. Pesquisa Agropecuária Brasileira, v.34, n.4, p.701-707, 1999.

ROELOFS, J.B.; GRAAT, E.A.M.; MULLAART, E.et al. Effects of insemination-ovulation interval of fertilization rates and embryo characteristics in dairy cattle. Theriogenology, v.66, n.9, p.21732181, 2006.

RUAS, J.R.M.; TORRES, C.A.A.; BORGES, L.E.et al. Concentrações plasmáticas de colesterol, glicose e uréia em vacas zebuínas, em relação à condição corporal e status reprodutivo. Revista Brasileira de Zootecnia, v.29, n.6, p.2036-2042, 2000.

RUEDA, P.M. Alterações comportamentais e hematológicas em vacas Nelore submetidas a protocolo de inseminação artificial em tempo fixo. 53f. Campo Grande, 2009. Dissertação (mestrado). Pós-Graduação em Ciência Animal. Universidade Federal do Mato Grosso do Sul.

SÁ FILHO, M.F.; GIMENES, L.U.; SALES, J.N. et al. IATF em novilha. Biotecnologia da Reprodução em Bovinos (3 Simpósio Internacional de Reprodução Animal Aplicada) Anais... Londrina, p.54-67, 2008a.

SÁ FILHO, M.F.; MARQUES, M.O.; BARUSELLI, P.S. Indução de ciclicidade e IATF em novilhas zebuínas. Biotecnologia da Reprodução em Bovinos (4ํㅗำósio Internacional de Reprodução Animal) Anais... Londrina, p.79-100, 2010.
SÁ FILHO, M.F.; SALES, J.N.S.; CREPALDI, G.A. et al. Effect of different ovulation inductors on pregnancy rates of Nelore (Bos indicus) heifers synchronized to fixed-time artificial insemination.. In: II International Symposium on Animal Biology of Reproduction, 2008, São Paulo. Animal Reproduction, v.6. p.307-307, 2008b.

SANTOS, L.L.; SEABRA JUNIOR, S.; NUNES, M.C.M. Luminosidade, temperatura do ar e do solo em ambientes de cultivo protegido. Revista de Ciências Agro-Ambientais, v.8, n.1, p.8393, 2010.

SCHUH, H. Comparison between liquid and deep-frozen semen for artificial insemination in developing and developed countries. World Animal Review, v.70-71, p.44-53, 1992.

TENESSEN, T.; PRICE, M.A.; BERG, R.T. Comparative responses of bulls and steers to transportation. Canadian Journal of Animal Science, v.64, p.333, 1984.

TORRES-JÚNIOR, J.R.S.; SÁ FILHO, M.F.; GIMENES, L.U.et al. Efeito da administração de PGF2 $\alpha$ no início do tratamento com implante auricular de norgestomet na dinâmica folicular de novilhas Nelore (Bos indicus). Reunião Sociedade Brasileira de Reprodução Animal, p.222, 2005

WATSON, P.F. The causes of reduced fertility with cryopreserved semen. Animal

Reproduction Science, v.60-61, n.2, p.481492, 2000. 